\title{
Reterritorializando el flujo de mano de obra extranjera: el nacimiento de una institución total nueva en la agricultura catalana
}

\author{
Olga ACHÓN RODRÍGUEZ \\ GRECS (Grupo de Investigación sobre Exclusión y Control Sociales) \\ Universidad de Barcelona \\ olga_achon@yahoo.es
}

Recibido: 27-11-2011

Aceptado: 03-04-2012

\begin{abstract}
RESUMEN
El sindicato agrícola Unió de Pagesos ha instaurado en el agro catalán un sistema diseñado para el control social del extranjero y la disposición permanente de trabajadores. La política migratoria española ha sido responsable de la emergencia de un sistema tal, del que es posible trazar su origen a través del estudio de los intereses que convergen en su instauración, esto es el control social de los extranjeros y el suministro just in time de temporeros. En el alojamiento se pretende la docilización de los hombres a través de diversos dispositivos (normativa, presencia de personal encargado, regímenes de visita y permisos de salida). Su carácter penitenciario y su tendencia totalizadora, nos lleva a la comparación de estos establecimientos con lo que Erving Goffman denominó Institución Total. La marca de esta nueva institución es su liminalidad, característica de un espacio dedicado a la concentración de los hombres y a su transformación.
\end{abstract}

Palabras clave: mano de obra extranjera; leyes de extranjería; control social; alojamiento obrero; institución total.

\section{Re-territorializing the flux of foreign labor force: the birth of a new total institution in the Catalan agriculture}

\begin{abstract}
The agricultural union Unió de Pagesos has established on Catalan soil a system designed for the social control and the permanent disposition of foreign workers. The State's migration polity is responsible of the emergence of such a system, and we can trace its origin in the symbiotic relation between the State and the union, whose interests - the social control of the foreign worker and the just in time delivery of labor- are harmonized in it. In the lodgment a transformation is intended through different devices (lodgment regulations, the presence of personnel in charge, a visit regime and exit permissions, among others). Its particular penitentiary character and its tendency to totalize the social life inside, resembles what Erving Goffman called Total Institutions. The footprint of this new institution is its liminality, characteristic of this space devoted to the concentration of men and their transformation.
\end{abstract}

Key words: foreign manpower; immigration laws; social control; workers accommodation; total institutions. 


\title{
Reterritorializando o fluxo de mão de obra estrangeira: o nascimento de uma instituição total nova na agricultura catalã
}

\begin{abstract}
RESUMO
O sindicato agrícola Unió de Pagesos instaurou no agro catalão um sistema desenhado para o controle social do estrangeiro e a disposição permanente dos trabalhadores. A política migratória espanhola foi a responsável da emergência de um sistema como este, do qual é possível traçar sua origem a través do estudo dos interesses que convergem em sua instauração, nomeadamente o controle social dos estrangeiros e o fornecimento just in time de trabalhadores temporários. No alojamento, pretende-se a domesticação dos homes a través de dispositivos diversos (normas, presença de pessoal responsável, regimes de visita e permissão de saída). Seu caráter penitenciário e sua tendência totalizadora, nos leva à comparação destes estabelecimentos com o que Erving Goffman denominou Instituição Total. A marca desta nova instituição é sua liminaridade, característica de um espaço dedicado à concentração dos homens e à sua transformação.
\end{abstract}

Palavras chave: mão de obra estrangeira; leis de estrangeiros; controle social; alojamento operário; instituição total.

REFERENCIA NORMALIZADA

Achón Rodríguez, Olga (2011) "Reterritorializando el flujo de mano de obra extranjera: el nacimiento de una institución total nueva para la agricultura catalana". Geopolítica(s). Revista de estudios sobre espacio y poder, vol. 2, núm. 2, 257-281.

SUMARIO: Introducción. 1. La investigación: datos y metodología. 2. El alojamiento: dispositivo de poder. 3. El alojamiento: una nueva institución total para el campo catalán. 4. Reterritorializando el flujo de extranjeros: táctica para el consumo intensivo de mano de obra. Conclusiones. Bibliografía.

\section{Introducción}

Los sistemas de fijación de mano de obra han representado en la historia del desarrollo de los distintos sistemas de producción soluciones al problema fundamental de la libertad de los hombres, presagio de una posible deserción del trabajo. Estos han sido establecidos de manera diversa: asignación de lugares específicos dentro de la escala social a los individuos que la integran; vinculación forzosa de los hombres a una actividad económica - dentro de un espacio geográfico concreto o un área de producción específica-; establecimiento formal de la obligación de trabajar y el consecuente control de la vagancia, o cosificación de los individuos y su atribución a un tercero que pueda disponer de ellos. Tales sistemas suelen conllevar la creación de estatutos jurídicos diversos que los legitiman, así como el establecimiento, en algunos casos, de instituciones dispuestas para impedir la fuga de las fuerzas productivas.

Pareciera que son las sociedades cuya estructura se cimenta sobre divisiones estancas, al estilo de las castas o estamentos feudales, las que en menor grado preci- 
san de este tipo de instituciones, pues ellas mismas vienen configuradas como una gran prisión de la persona. En ellas no es posible gozar de libertad suficiente para alterar su posición en la escala social. Por el contrario, las sociedades que consienten la porosidad de las fronteras sociales por las cuales se efectúan tales divisiones y en las que, por tanto, los individuos que las constituyen son en mayor medida libres para iniciar procesos de movilidad entre lugares tanto estructurales como topográficos, suelen requerir la presencia de establecimientos en los que confinar la mano de obra en tanto en cuanto su autonomía supone un problema al desarrollo, consolidación o supervivencia de determinadas actividades económicas. Una paradoja de estas sociedades es la existencia de lugares destinados a la reserva de la fuerza de trabajo establecidos al amparo de leyes y estatutos jurídicos, o, siguiendo a Foucault, consecuencia del establecimiento en ellas de la libertad formal universal que las define (Foucault, 2000: 234).

El alojamiento para trabajadores extranjeros contratados en origen por el sindicato agrícola Unió de Pagesos no es una excepción a esta regla. Erigido con propósitos similares a aquellos que provocaron la aparición de la ergástula romana, la workhouse inglesa o el hospital francés, constituye una reserva de mano de obra destinada a auxiliar un sector económico del que han desertado aquellos cuyas cotas de libertad son superiores debido a su mayor poder social. Su forma, análoga a las instituciones apuntadas pero también en cierto modo a una cárcel o un acuartelamiento militar, sirve, en efecto, para repartir, fijar y distribuir espacialmente a los hombres, clasificarlos para obtener de ellos el máximo posible de su tiempo y fuerzas, educar su cuerpo y codificar su comportamiento, mantenerlos visibles al poder que los somete, no solamente mediante la configuración de un espacio arquitectónicamente idóneo para ello, sino atrapándolos en una red de registros y anotaciones con el fin de obtener un saber que se acumula y centraliza. Producto específico del sistema que permite su establecimiento y que constituye objeto de este estudio, el alojamiento se presenta como el lugar apropiado para la constatación de aquello que tal sistema produce, esto es, el cercenamiento del ejercicio de libertades personales $^{1}$ y la producción de un sujeto privado del ejercicio de derechos fundamentales entre los que se encuentran, principalmente, la libertad de trabajo y consecuentemente la de circulación y la de domicilio.

\footnotetext{
${ }^{1}$ A este respecto ya apuntaba Juana Moreno Nieto lo siguiente para el caso de las trabajadoras marroquíes en Huelva: "La cuestión de la tutela en las distintas fases del proceso lleva a introducir el concepto de estatus cautivo que utiliza Binford [...] para referirse a los temporeros mexicanos contratados en origen en los campos de agricultura intensiva canadiense. Este concepto se presenta valido para describir la situación de las temporeras de los campos freseros de Huelva, cuya contratación da lugar a una transacción por la que a cambio de trabajar legalmente en el país, éstas ceden parte de sus libertades asociadas con un mercado de mano de obra libre. No tienen poder para desplazarse en el mercado de trabajo, ni para negociar sus condiciones de trabajo o elegir empleador" (2009: 74).
} 
La primera aproximación al contexto de la investigación que da lugar a este artículo se produce gracias a la contratación de la autora como encargada de alojamiento en Montblanc para llevar a cabo tareas de gestión durante la campaña de la vendimia en el año 2003. Durante los dos meses en los que ésta se desarrolló tuvimos la oportunidad de observar desde una posición privilegiada lo que allí acontecía. En su interior se advertía la sutil dominación que sobre los hombres se operaba, por lo que nos dispusimos a la observación atenta del modo en que se instauraban las relaciones entre los que ejercitaban el poder del sindicato y los trabajadores. Nació de esta primera experiencia la inclinación por comprender las razones y el modo en que tal ejercicio de poder se llevaba a cabo. Las características del espacio que obligaba a la realización de actividades en común con el resto de los que allí estaban presentes, la sujeción de los alojados a un régimen común de vida reglamentado, la presencia de personal encargado con capacidad para sancionar las conductas no deseadas por el sindicato, nos condujo a la interpretación del mismo como emparentable con lo que Goffman había definido como institución total. Considerada desde esta perspectiva, no se pudo sino asimilarla en cierta medida a establecimientos que, como las cárceles o los campos de trabajo, tienen como finalidad - siguiendo a Goffman - la protección de la comunidad contra quienes constituyen un peligro para ella o se erigen en instrumentos al servicio del control de la mano de obra (Goffman, 2007: 18).

\section{La investigación: datos y metodología}

Desde una perspectiva de análisis centrada en la observación directa de la interacción social de los actores reunidos en los establecimientos objeto de estudio, por la que tratamos de examinar las estructuras básicas de dominación, así como a través de la descripción de los lugares y estudio de los aspectos político-normativos que han posibilitado la emergencia de la institución-alojamiento es que hemos desarrollado la investigación cuyo resultado se presenta en este artículo. En el mismo tratamos la territorialización de los sujetos en un espacio concreto diseñado para el consumo intensivo de la fuerza de trabajo. Tal fijación se logra a través del cercenamiento de derechos tales como el de circulación y trabajo, logrado merced a la imposición de obligaciones por parte del sindicato agrícola Unió de Pagesos a los trabajadores que selecciona, importa, concentra y suministra, que son consideradas parte de las condiciones de trabajo. Consecuencia de la imposición de tales condiciones laborales, por las que la delimitación entre vida privada y ámbito del trabajo se torna inexistente, es que llegamos a la interpretación del establecimiento como un dispositivo de poder dispuesto para la docilización de la mano de obra a través de la imposición de disciplina por parte del Sindicato.

Asimismo desarrollamos en este artículo un análisis del alojamiento considerado desde el punto de vista de su función docilizante frente a las resistencias que tradi- 
cionalmente los trabajadores han opuesto a la imposición de disciplina. Una serie de analogías históricas sirven a este propósito, presentando diversos conjuntos habitacionales dispuestos para trabajadores y las fábricas en que trabajan. Unos y otros se asemejan a la institución objeto de estudio en la imposición de disciplina y el propósito de sumisión de la mano de obra para rebelarse contra el orden impuesto en el interior de los lugares de trabajo y de vida de los trabajadores.

Finalmente proponemos el estudio del alojamiento dispuesto para los trabajadores contratados en origen por la Unió de Pagesos como una institución total. Siguiendo esta categoría de análisis llegamos a concluir que su aparición en el agro catalán sirve a los efectos de la dominación del extranjero en general y de este trabajador contratado en origen, en particular. Igualmente su surgimiento se vincula con el interés del Estado por erradicar la presencia del extranjero pobre del espacio público. Así, disciplina para el trabajo y el mantenimiento del orden público, tanto Sindicato como Estado se benefician, toda vez que el alojamiento sirve a los objetivos de la sujeción de la mano de obra y su constante disponibilidad y el control social del extranjero pobre.

Para la realización de la investigación - desarrollada entre los años 2003 y 2011 - y así llegar a las conclusiones que presentamos en el presente artículo, fue necesario realizar visitas a alojamientos colectivos gestionados por la Unió de Pagesos, tanto de titularidad de empresas agroalimentarias, como de entes locales, generalmente ayuntamientos que los ceden al conjunto de agricultores de su municipio que emplean trabajadores a través del sindicato (Figura 1). De aquéllos, la mayor parte se concentraban en la comarca del Segrià, seguida de l'Urgell y el Plà d'Urgell, por lo que fue en estas demarcaciones que realizamos el trabajo de campo. Esta opción metodológica encuentra su fundamento en la mayor densidad de alojamientos colectivos en la comarca del Segriá. De tal modo realizamos trabajo de campo en el Segrià específicamente en Alcarràs, Alcoletge, Soses, Torres de Segre, Artesa de Lleida, Puigverd de Lleida, Corbins, Aitona y Serós, municipios en los que se visitaron doce alojamientos colectivos, tanto de empresa como públicos. En el Plà d'Urgell recorrimos seis alojamientos situados en Bell-lloc, Bellvís, Mollerusa y Miralcamp. Para el caso de l'Urgell visitamos tres alojamientos en los municipios de Bellpuig, La Fuliola y Verdú. Adicionalmente se realizaron visitas a alojamientos en Montblanc, Les Pobles y Batea, pertenecientes a diversas comarcas que no son tan representativas como las anteriores, pues cuentan con menor número de alojamientos.

Estos establecimientos conformaron el terreno sobre el que realizamos las visitas necesarias para la elaboración de las diversas tipologías de alojamiento y su descripción. En ellos tuvimos la oportunidad de trabar contacto con las encargadas y los trabajadores que formarían parte del grupo de informantes, a los que entrevisté tanto al interior del alojamiento, como en su exterior. Sin embargo, las informaciones que nos auxiliaron en la tarea de la interpretación y el análisis - tanto al respecto de lo que en tales establecimientos sucedía, como sobre lo que su implantación 
para el empresariado agrícola significaba, o como lo que su aparición en el municipio había representado - provinieron, además, de un sinfín de encuentros casuales. Agricultores, tanto contratantes del servicio de suministro de mano de obra de Unió de Pagesos, como otros cuya preferencia a la hora de hacerse con la fuerza de trabajo consistía en el empleo de trabajadores extranjeros en situación irregular o en la contratación de los servicios de gestorías y ETT's; vecinos de los municipios, en ocasiones involucrados en el establecimiento de la red de alojamientos debido, esencialmente, a los negocios de alquiler de inmuebles a los ayuntamientos interesados en dotar de espacios para el albergue de trabajadores a los empresarios agrícolas.

Figura 1. Alojamientos visitados durante el trabajo de campo (por municipio y comarca)

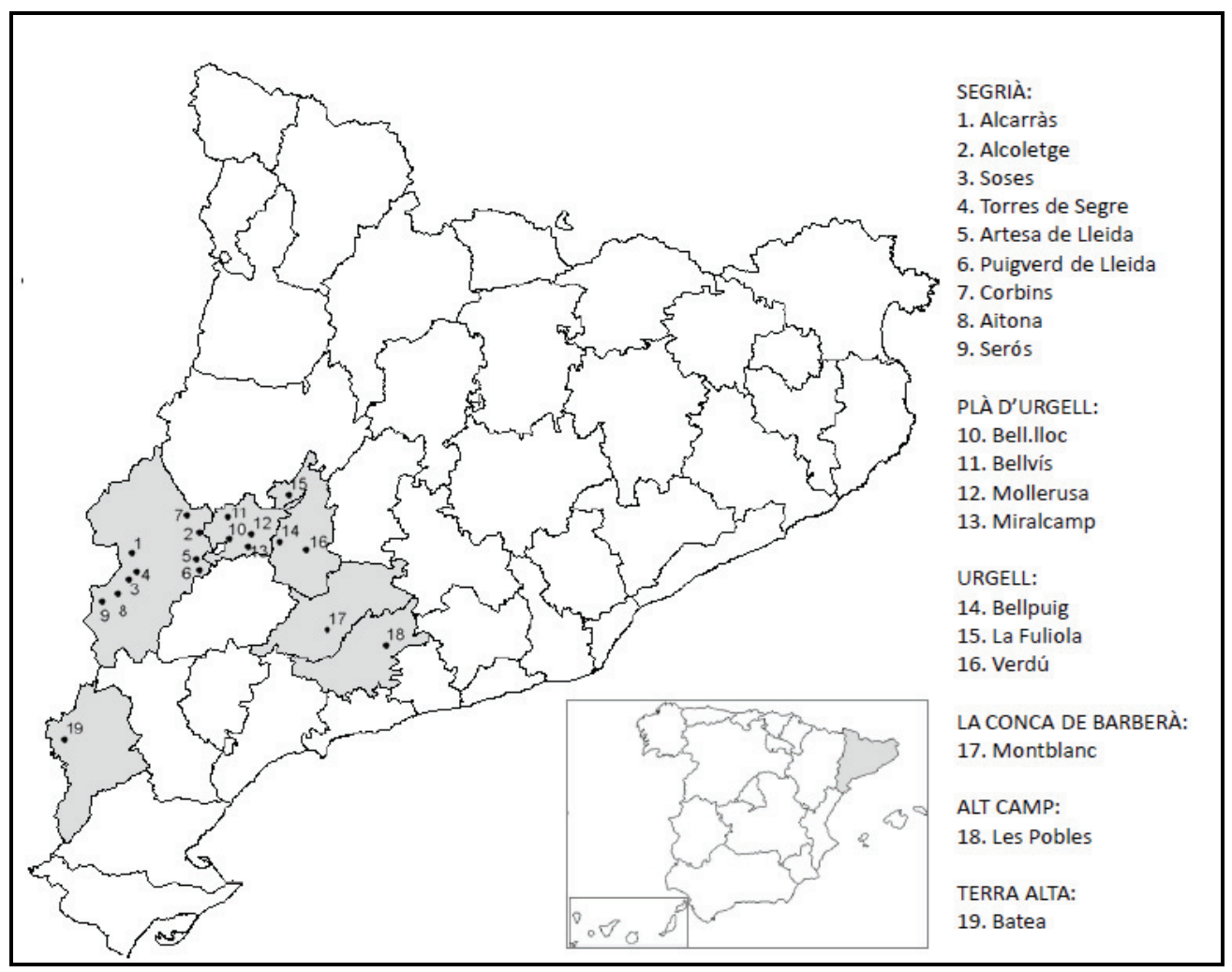

Fuente: elaboración propia 
A su vez, extranjeros en busca de trabajo, entre otros, nos proporcionaron información a través de conversaciones informales en marcos tan variados como un descampado, un campo de perales, una panadería, una pequeña plaza de pueblo o las escaleras de una iglesia. Cuando estos encuentros se daban, el recurso al diario de campo se tornó imprescindible. En él se anotaron valiosas impresiones sobre cada acontecimiento, intuiciones sobre lo sucedido y pequeñas reflexiones que irían transformándose a medida que la investigación avanzaba. Las descripciones de los establecimientos serían igualmente consignadas en este preciado cuaderno llegando a constituir el diario de abordo de esta singular expedición.

En cuanto a las entrevistas en profundidad, se efectuaron siguiendo un guión estructurado para garantizar la discusión sobre temas relacionados principalmente, para el caso de los trabajadores, con la experiencia como interno, con el tipo de alojamientos en los que cada entrevistado residió, animando a su descripción y al relato de aspectos relacionados con el proceso de selección, reclutamiento y suministro, así como aquéllos relativos a la ejecución del trabajo en el interior de empresas y campos. Respecto a los esquemas confeccionados para entrevistar al personal encargado, preferimos centrarnos en temas vinculados esencialmente al trabajo cotidiano que ejecutaban en relación con la gestión del grupo, la evaluación de actitudes de los trabajadores, la imposición de sanciones, las tareas relativas al suministro de mano de obra, así como su formación profesional y el tipo de alojamientos en los que desempeñó tales funciones.

A este respecto, el hecho de que el personal encargado informante sea femenino, debe señalarse que no responde a una criba que intencionalmente se haya efectuado, sino que es consecuencia de la selección deliberada de mujeres por parte del sindicato para desarrollar este tipo de trabajo. Aunque no hay manera de constatar explícitamente los motivos de esta práctica, puede inferirse que responde a una serie de convicciones que los contratantes comparten acerca de las mujeres como sujetos con mayor apego a las normas y, por ello, con un mayor rango de cumplimiento de las órdenes dictadas, así como una superior identificación con el objetivo perseguido por el sindicato, y la percepción del trabajo a desempeñar como una actividad de carácter social y, en consecuencia, identificada con roles asociados culturalmente a la mujer.

De forma similar debemos advertir acerca de la procedencia de los trabajadores entrevistados, en su mayor parte originarios de Colombia y Rumanía, pues es en estos países donde se realizaba principalmente el proceso de reclutamiento durante el período en que se desarrolló el trabajo de campo. Debido a que para mí resultaba más sencillo comunicarme con los trabajadores colombianos que con los rumanos - puesto que no todos estos últimos hablaban fluidamente el castellano-, resulta el hecho de que los primeros resultan ser más significativos en el conjunto de informantes.

Sobre la composición por sexo de los informantes, debemos realizar ahora algunas puntualizaciones. La razón que explica la presencia exclusiva de hombres en 
nuestra investigación es que ésta se ha centrado, principalmente, en el análisis de los alojamientos colectivos de titularidad pública - denominados por el sindicato como "comunitarios"-, pues en ellos suele albergase a trabajadores dispuestos al suministro constante para diversos empresarios agrícolas. La naturaleza de este tipo de alojamientos, que nos obliga a considerarlos como nódulos de suministro destinados al abastecimiento de mano de obra contratada en origen en favor de un amplio número de agricultores de un mismo municipio, explica mi preferencia por su estudio. En ellos se concentra predominantemente mano de obra masculina, resultado de la convicción que los agricultores comparten de que el tipo de trabajo a desarrollar en sus explotaciones frutícolas requiere una gran fuerza física, tanto por su dureza como por las condiciones climatológicas bajo las que se ha de desarrollar. Así, mientras que en los establecimientos dispuestos en los alrededores de las plantas de envasado se encuentra en mayor porcentaje mano de obra femenina, en la categoría de alojamientos comunitarios la presencia masculina es predominante. $\mathrm{La}$ segmentación del mercado de trabajo agrícola por razones de género se encuentra por tanto puesta de manifiesto en nuestra muestra. Del mismo modo en que se alude a la feminización del colectivo temporero dedicado a labores de recolección de la fresa en Huelva (Gordo Márquez y Felicidades García, 2009: 167), puede entonces denominarse los efectos derivados de la tendencia de los agricultores a contratar mano de obra masculina en explotaciones dedicadas a la fruticultura como masculinización del mismo.

\section{El alojamiento: dispositivo de poder}

Como veremos más adelante, mediante la normativa, reglamento por el que se rige la vida al interior del alojamiento, se manifiesta la vocación del sindicato por fijar aquellos obstáculos que, evocando una vez más a Erving Goffman y su caracterización de las instituciones sociales ${ }^{2}$, se podría decir que "se oponen a la interacción

\footnotetext{
${ }^{2}$ Como se recordará, Goffman, en las primeras páginas de Internados, se encarga de definir las instituciones totales como establecimientos sociales - es decir lugares - que absorben de manera absoluta o casi absoluta el tiempo y el interés de quienes en ellos se encuentran. Esa función absorbente se mide por los obstáculos que se oponen a la interacción social con el exterior y al éxodo de los miembros, y que suelen adquirir forma material: puertas cerradas, altos muros, alambre de púa, acantilados, ríos, bosques o pantanos. En estos sitios todos los aspectos de la vida se desarrollan en el mismo lugar y bajo la misma autoridad única; cada etapa de la actividad diaria del miembro se lleva a cabo en compañía inmediata de un gran número de otros, a quienes se da el mismo trato y de quienes se requiere que hagan juntos las mismas cosas; todas las etapas de las actividades diarias están estrictamente programadas, de modo que una actividad conduce en un momento prefijado a la siguiente, y toda la secuencia de actividades se impone desde arriba, mediante un sistema de normas formales explicitadas, y un cuerpo de funcionarios; las diversas actividades obligatorias se integran en un solo plan racional, deliberadamente concebido para el logro de los objetivos propios de la institución, $\mathrm{y}$, por último, se registra una escisión básica entre un gran grupo de internos que vive o pasa buena parte de
} 
social con el exterior y al éxodo de los miembros" (Goffman, 2007: 18). Su presencia explicita la tendencia absorbente o totalizadora, siempre en terminología de Goffman, del establecimiento objeto de análisis, que, en efecto, se caracteriza en buena medida por la apropiación del tiempo de los que allí se encuentran, por el intento de supresión de una voluntad autónoma para el desarrollo de las actividades cotidianas y por el remplazo de un régimen de vida propio por otro impuesto. Ese régimen impuesto implica la supresión de las fronteras delimitadoras de los distintos espacios en los que se desarrollan un buen número de actividades cotidianas, su ejecución en un único lugar — bajo la dirección de una sola autoridad-, a través de un único programa - exigido por un grupo de funcionarios adscritos a una jerarquía-, y en compañía de otros sujetos que comparten el mismo estatus de internos.

En su estudio Goffman propone una tipología de las instituciones sociales. Uno de los tipos se correspondería con aquellas que están organizadas para proteger la comunidad contra quienes puedan constituir intencionalmente un peligro para ella, a la manera como hacen, por mencionar los ejemplos que el propio Goffman sugiere, las cárceles, los presidios, los campos de trabajo y de concentración. Otra variante estaría compuesta, según la tipología goffmaniana, por sitios destinados al mejor cumplimiento de una tarea de carácter laboral, y que sólo se justifican por estos fundamentos instrumentales: los cuarteles, los barcos, las escuelas de internos, los campos de trabajo y los diversos tipos de colonias. Ciertamente, el alojamiento destinado a los trabajadores presenta semejanzas con estos dos tipos de instituciones, las que se relacionan con los distintos propósitos pretendidos por los agentes que promovieron su instalación, es decir Estado y sindicato ${ }^{3}$. La regulación del flujo migratorio y el establecimiento de obstáculos jurídicos a la radicación de extranjeros en el país, así como, la instalación de un negocio de importación y suministro de mano de obra, son los intereses que por el alojamiento se procuran alcanzar y que nos remiten al tipo ideal propuesto por Goffman. ${ }^{4} \mathrm{La}$ amenaza de la formación de bolsas de marginados, excluidos intencionalmente de los sistemas normalizados de funcionamiento social con el fin de sacar de ellos un provecho económico como mano de obra barata, y el peligro que entraña el sujeto que las configura, libre para abandonar el trabajo y practicar su nomadismo, son los motivos que impulsan la

su tiempo dentro del establecimiento y al que se restringen sus contactos con el exterior, y un pequeño grupo de personal supervisor que cumple una jornada laboral y que está socialmente integrado en el mundo de afuera (Goffman, 2007).

${ }^{3}$ Para el caso onubense, Moreno Nieto (2009: 76) considera adecuada y sugerente la designación del campo agrícola como Institución Total que Binford realizó en su trabajo sobre la agricultura canadiense y mexicana, si bien para nosotros la Institución Total se realiza en el contexto del alojamiento.

${ }^{4}$ Acaso sea este el momento de hacer notar que otros antropólogos han formulado aproximaciones etnográficas a instituciones totales, siguiendo el referente teórico provisto por Goffman. Por citar dos ejemplos cercanos, véase el trabajo de José Luis Anta Félez sobre un acuartelamiento militar (Anta, 1986), y el de Josep María Comelles sobre un hospital psiquiátrico en Barcelona (Comelles, 2007). 
elaboración de una estrategia que procura su aislamiento, implementada por el Estado, a fin de erradicar del espacio público al extranjero errante. Premonición de un riesgo más urgente - la desestabilización de la paz social y el resquebrajamiento de lo que se supone que es un sistema democrático de derecho-, imperceptible a una sociedad y un Estado indiferentes, la figura de este extranjero debe ser suprimida y reemplazada por otro más sumiso y dócil a las exigencias del capital y de una geografía libre del germen del desorden. A tales efectos, el alojamiento se presenta como una solución alternativa al simple internamiento, económicamente más rentable, por responder a las exigencias de un encierro productivo. Nuevamente se confirma lo que ya observaran Fourquet y Murard a propósito de la formación del Estado, el desgajamiento del Antiguo Régimen y la distribución de las masas de población en espacios sociales cerrados, que "todo lo que es capaz de fluir detona un nuevo equipamiento colectivo" (Fourquet y Murard, 1978: 78).

La estructura de asilo que posee este establecimiento - válvula que permite una movilidad controlada y clausura que elimina el riesgo inherente de la muchedumbre libre a tomar las riendas de su propio destino - y la disciplina cuartelaría que en el mismo se dispensa - dispositivo para la doma del sujeto que alberga, útil a su movilización forzada - nos remiten efectivamente a los subtipos de Goffman al que pertenecen cárceles, los correccionales, las colonias o los campos de trabajo. En todos ellos quien es al mismo tiempo un peligro y una fuerza de trabajo, como si de una operación simultánea de purificación y control se tratase, se confina y se trata a modo de una terapia correctiva con el fin de la reproducción de una dominación social. Se tornan semejantes en este punto los presos de las cárceles, los prisioneros de los campos de concentración, los reclusos de los centros de internamiento para extranjeros y los trabajadores de los alojamientos. Para todos ellos un régimen de vida similar les ha sido impuesto, relacionado con el objetivo de su clausura y su transformación, presente en las instituciones que éstos pueblan. En efecto, el tipo de habitación considerado, contemplado por el tipo de administración que lo gobierna, toma forma de institución total prevista al sostenimiento de un "tipo particular de tensión entre el mundo habitual y el institucional" (Goffman, 2007: 26), necesaria al disciplinamiento y, por lo tanto, a la producción del trabajador sumiso. Manifestaciones de esta oposición del mundo al interior del alojamiento y al exterior del mismo, no son sino exteriorizaciones de su tendencia totalizadora, entre las que destacan los procedimientos de ingreso, de traslado o los de suministro. La figura de la prisión permanece tras el alojamiento del mismo modo en que se hallaba presente en multitud de instituciones que durante el siglo XVII terminaron configurando lo que Foucault denominó la época del gran encierro. Establecidas con el objetivo del disciplinamiento y el control social de poblaciones condenadas por su errancia, pobreza y desocupación, su fundación anunció el inicio de un nuevo modelo de 
sociedad presta a la condenación de la ociosidad del vago y la inutilidad del mendigo ${ }^{5}$. El Hospital General francés es, desde este punto de vista, el antecedente del alojamiento en cuanto su establecimiento ha venido igualmente precedido de una ética utilitarista, que concibe al hombre cual objeto funcional a los fines de la maximización del bienestar del mayor número de individuos, y de una práctica generalizada del confinamiento de aquellos sentenciados a garantizar el goce del placer de tal mayoría. Figuras posteriores, como las workhouses en Inglaterra, no son sino manifestación de la radicalización del fenómeno de la entronización del trabajo como valor social y el aprovisionamiento autoritario de mano de obra forzada (Gaudemar, 1981: 31). El trabajador contratado en origen resulta ser, entonces, la encarnación contemporánea del loco, como el alojamiento la representación del espacio del encierro.

\section{El alojamiento: una nueva institución total para el campo catalán}

Una de las características principales de todo alojamiento comunitario es la presencia en su interior de personal encargado de su gestión. La concepción de este establecimiento como un dispositivo de poder lo requiere, pues es él quien se ocupa del manejo de todo el conjunto de discursos elaborados por el sindicato, de los reglamentos que rigen su uso, así como de las medidas que se adoptan, de tipo administrativo y sancionatorio, en el transcurrir diario de la vida al interior del mismo. El alojamiento-dispositivo de poder no es sino todo este conjunto de elementos, orientados al control social de los que allí se internan, cuyo entrecruzamiento produce una red tupida de órdenes, estrategia que permite la inserción de una práctica represiva del ánimo libertario de los trabajadores. Es una formación específica cuya función es, al decir de Foucault, la de responder a una urgencia, por lo que el carácter de su posición es esencialmente estratégica (Foucault, 1991: 129). La concentración, adecuada a la vigilancia de un sujeto doblemente peligroso por su cualidad de extranjero y trabajador, y la forma de gobierno autoritario que allí opera, por la que los individuos quedan entregados a un proceso docilizador, son resultado de un sistema que pretende su explotación sistemática, su transformación en mano de obra rentable (Foucault, 1991: 93). De ningún otro modo es posible la acumula-

\footnotetext{
${ }^{5}$ Emmanuel Rodríguez reflexiona sobre el problema del disciplinamiento de las poblaciones errantes del siguiente modo: “«Hacer trabajar» a los desocupados, impedir las constantes fugas de las fábricas era, quizás, el principal problema de los primeros capitanes de la industria. Se trataba de fijar físicamente a los trabajadores, de promover los valores de una vida estable, disciplinada, asentada en torno a la realidad de la familia. En este sentido, los métodos disciplinarios como las workhouses o la cárcel no agotaban plenamente la posibilidad siempre abierta de la defección del trabajo: la delincuencia, el vagabundeo, la inmigración" (2003: 26).
} 
ción de capital, sino a través de la "acumulación de hombres" — en expresión de Fernando Álvarez-Uría y Julia Varela- sometidos por el ejercicio del poder (Foucault, 1991: 22). El arte de su gobierno lo desarrolla la figura del encargado a través del establecimiento de relaciones que lo vinculan con sus superiores jerárquicos y con los trabajadores. Por medio de estas relaciones se ejercita el poder del sindicato y se configura la institución del alojamiento que, mucho más allá de su instalación arquitectónica, resulta ser "todo comportamiento más o menos forzado, aprendido. Todo lo que en una sociedad funciona como sistema de coacción sin ser enunciado" (Foucault, 1991: 132).

Principal función del personal encargado es el ejercicio de la disciplina, dirigido a la transformación de hombres amenazantes de la sociedad y su identidad cultural en elementos funcionales a la producción. Su misión es similar a la de un timonel que guía una máquina de poder semejante, en sus funciones, a aquella ingeniada por Bentham con la finalidad, en palabras de Josep Ramoneda, de "hacer de los delincuentes hombres útiles para el proceso de producción, de acuerdo con las necesidades de un tiempo en que no convenía que nadie se escapase de la cadena de acumulación de capital" (Bentham, 1985: 5). La consecución de un orden adecuado a la producción que sirva al mantenimiento de un fluir constante de la mano de obra es el objetivo que persigue el sindicato. El alojamiento, por su capacidad concentradora, y el gobierno que allí se instaura se encaminan a la eliminación de resistencias, pues lo que no debe permitirse es la creación de presas que inhiban el movimiento. Para ello es preciso estructurar todo lo que concierne al espacio que los alberga, con la clara intención de "asegurarse de sus actos, sus relaciones, todas las circunstancias de su vida, de tal manera que nada pudiese escaparse ni oponerse al efecto deseado" (Bentham, 1985: 31). Podemos incluso determinar una similitud entre el establecimiento, objeto de análisis, y el panóptico ideado por Bentham, pues ambos se refieren al objetivo de la maximización del ejercicio de un poder transformador del sujeto, inserto en tales establecimientos, en un individuo dúctil a sus deseos. Un poder, diremos, interesado en la conducta de aquellos a los que somete que no aspira a conversión espiritual alguna, que no pretende persuadir de la benevolencia del tratamiento dispensado, sino un poder al que solamente estimula la comprobación de un resultado externo: la gestión maquinal del movimiento.

La lógica panóptica sobre la que se asienta organiza la vida al interior del alojamiento y determina la tarea del encargado, que debe asimilarse a la del vigilante, encarnación del poder. La inspección es el procedimiento por él empleado con el fin de instaurar el orden y mantenerlo. Para ello es necesaria la censura de determinadas acciones consideradas perjudiciales a las finalidades transformadoras del sistema. El detalle de las mismas se dispone en un reglamento particular denominado 
normativa de alojamiento ${ }^{6}$. Heredera de antiguos reglamentos de régimen interior, dispuestos con el fin de extender más allá de los confines de fábricas y explotaciones mineras o agrícolas la disciplina funcional a los objetivos de la producción, la normativa del alojamiento se impone con el firme propósito de erradicar conductas que procuren una resistencia al sistema y de proponer, a su vez, un modelo de comportamiento.

Un ejemplo español del empleo de este tipo de estrategia disciplinaria se encuentra en el poblado minero de Bustiello, "fundado en 1890 por el primer marqués de Comillas y potenciado por el segundo, Claudio López Bru, [...] hizo realidad los sueños más delirantes de cualquier ciudad utópica". Esta jaula de oro, así denominada por los afiliados del Sindicato Minero Asturiano, "se regía por un reglamento propio, con su policía particular, su servicio de información a cargo de los capataces

\footnotetext{
${ }^{6}$ Transcribimos a continuación este particular código propuesto en el Proyecto de gestión de los alojamientos y seguimiento de los trabajadores (2005), elaborado por la Unió de Pagesos:

"1. El descuento en materia de alojamiento está regulado legalmente: será como máximo del 10\% del salario y con derecho a uso limitado a la duración del contrato.

2. Está prohibido el consumo y la posesión de drogas y alcohol en el alojamiento.

3 . No se puede fumar en las habitaciones.

4. Se deben respetar los objetos personales, las instalaciones y el mobiliario: Unió de Pagesos no se hace responsable de los objetos personales ni del dinero de los trabajadores (se les recomienda guarden su dinero en entidades bancarias).

5. Cualquier desperfecto que se detecte dentro del centro se comunicará al encargado del alojamiento.

6. Todo el material que se proporcione se devolverá una vez finalizada la estancia en el centro, si no se deberá abonar el total de su coste. Será opcional (a criterio del propietario/os del alojamiento) adelantar cierta cantidad en concepto de fianza.

7. Es necesario mantener unas condiciones básicas de higiene personal para favorecer la convivencia.

8. Los trabajadores deben responsabilizarse de la limpieza y del orden de las instalaciones del alojamiento.

9. Cada trabajador limpiará sus utensilios después de cada comida; para evitar aglomeraciones la ropa y las sábanas se limpiarán según los turnos establecidos.

10. Se respetará a todas las personas independientemente de su cultura, religión, sexo o procedencia.
}

11. Las conductas que alteren el orden o la apropiación indebida de objetos ajenos quedarán sujetas a los criterios técnicos de aplicación en el alojamiento.

12. La provocación y/o participación en peleas u otros altercados físicos y/o verbales quedarán sujetas a los criterios técnicos de aplicación en el alojamiento.

13. Se debe respetar los horarios de descanso, de $24 \mathrm{~h}$. a $7 \mathrm{~h}$. y de 14:30 h. a 15:30 h., por defecto.

14. Por respeto a los compañeros del alojamiento, no se puede acceder ni salir del centro en horario nocturno de descanso (a partir de las $24 \mathrm{~h}$.), excepto en la víspera de festivos.

15. Por razones de seguridad y protección, no están permitidas las visitas ni la utilización de los alojamientos sin previo consentimiento de los técnicos de la Unió.

16. Se debe colaborar con los encargados para mejorar la comunicación y aclarar todo lo que pueda repercutir en uno mismo o en el grupo.

17. En caso de cualquier evidencia clara de no cumplimiento de la normativa se deberá permitir las inspecciones de los responsables del alojamiento.

18. Es imprescindible leer este documento y firmarlo aceptando las condiciones.

EL NO CUMPLIMIENTO DE ESTA NORMATIVA SUPONDRÁ LA APLICACIÓN DE LOS CRITERIOS DE RESOLUCIÓN DE INCIDENCIAS." 
y una especie de despotismo ilustrado teocrático, que rayaba en lo grotesco en algunos casos y que acabó por desilusionar a los presuntos beneficiarios de este «cielo en la tierra»" (Arias González, 2001-2002: 109).

Vemos así, en el pasado como en el presente, como el poder se expande a manera de una gran sombra, con la intención de tomarse los intersticios en los que se guarecen los residuos de una, supuestamente aniquilada, autonomía obrera. Con tal fin, el sindicato inicia una tarea de codificación de los comportamientos haciendo uso del lenguaje del poder, es decir, el lenguaje del Derecho, pues como ya señaló Foucault, "[t]odo el poder, ya sea de arriba abajo o de abajo arriba y cualquiera que sea el nivel en que se considere, se halla efectivamente representado, de un modo más o menos constante, en las sociedades occidentales, bajo una forma negativa, es decir, bajo una forma jurídica" (1991:135). Su uso determina una analogía, consignada por Foucault, entre las estructuras de poder de diversas instituciones (una prisión, un colegio, una fábrica, un asilo) a pesar de no perseguir idénticos objetivos. En efecto, existe una identidad morfológica del sistema de poder que en todas ellas se instala. El reglamento no hace sino evidenciar esta analogía. En este sentido, todas las resistencias que el sindicato procura suprimir están emparentadas con las distintas estrategias de evasión o de quiebre de la autoridad presentes en multitud de establecimientos dirigidos al disciplinamiento de conglomerados de sujetos. En todos ellos se lleva a cabo una misma revuelta, "porque es exactamente contra el mismo tipo de poder, digamos, contra el mismo poder, contra el que se rebela" (Foucault, 1995: 66).

Sin embargo, si existe un establecimiento que presente más similitudes, no solamente en relación al modo en que el poder opera, sino en relación a la finalidad económica que pretende, ese es la fábrica. Subsumimos, entonces, el alojamiento en una categoría de instituciones entre las que ésta se encuentra, pues lo que en ambos casos el poder pretende fabricar son trabajadores dóciles, útiles a la acumulación del capital. La normativa de alojamiento queda de este modo analogada a los reglamentos de fábrica, que han tratado, a lo largo de su historia, el disciplinamiento de los procesos productivos. Constituye, al igual que los códigos industriales, no solamente el mecanismo particular que fija el modo en que la disciplina debe operar, sino, como apunta Castillo Mendoza, "la más clara expresión de una hegemonía empresarial largo tiempo irreductible a los intentos de regulación estatal" (Gaudemar, 1991: 16). Por ellos se reproducen, al interior de los espacios fabriles, los modos de dominación sociales preexistentes, pues resultan —al menos durante su nacimiento y gran parte de su desarrollo - funcionales al sistema productivo capitalista, surgido en un contexto de abundancia de mano de obra barata. En cuanto estas condiciones le son dadas tanto al industrial inglés desde mediados del siglo XIX, como al empresario agrícola catalán hoy — gracias a la importación de miseria operada por el sindicato-, no dudarán en ejercer su poder despótico a través de códigos fabriles, en un caso, y normativas de alojamiento, por otro. Así, si "el capitalista formula en su código de fábrica — como legislador privado y a su buen placer- el poder 
autocrático que tiene sobre sus hombres [...], [si] no es otra cosa que la caricatura de la regulación social, tal y como la exigen la cooperación en grande y el empleo de medios de trabajo comunes, sobre todo el de las máquinas" (Marx, 1972: 444); la normativa de alojamiento no es sino el símbolo de la dominación ejercida sobre el extranjero, autorizada por el Estado, con la intención de sacar el máximo provecho posible a su desventura: ser pobre y constituir una gran masa. La comparación de ambos reglamentos ilustra la cercanía existente entre la posición de la burguesía inglesa decimonónica, quien al interior de los presidios mitigados - como denominó Charles Fourier a las fábricas (citado por Marx, 1972: 447) — creía conveniente la suspensión tanto de sistemas representativos como de regímenes basados en la división de poderes, y aquella adoptada por el Estado que garantiza el establecimiento de un espacio vacío de derecho en el que va a ser posible instaurar un orden conveniente a la restricción de libertades, útil al mantenimiento del sistema de poder por el que tal establecimiento se ha instaurado. Siguiendo a Marx, cierto es en nuestro caso, como lo fue para la fábrica manchesteriana o sheffieldiana, que "el látigo del conductor de esclavos es sustituido por el libro de sanciones del contramaestre" (Marx, 1972: 444).

A través del mismo es posible observar el modo en que el sindicato ha decidido someter al trabajador, pues al interior del alojamiento se ha erigido en legislador absoluto que "hace reglamentos según le venga en gana, modifica y amplía su código a su placer y, si introduce en él la arbitrariedad más extravagante, los tribunales dicen a los trabajadores: «Puesto que habéis aceptado este contrato voluntariamente, tenéis que someteros a él...»" (Marx, 1972: 445; Engels, 1976: 232). En efecto, los fabricantes del siglo XIX y el sindicato agrícola actual se muestran de forma similar, cual "acusador, testimonio, juez, legislador, ejecutor, todo en una persona" (Engels, 1976: 232). Igualmente, ambos hacen firmar al trabajador tanto normativas como reglamentos de fábrica en los que el mismo hace entrega de su consentimiento en la ejecución de lo pactado ${ }^{7}$. Así, la firma obligatoria de la norma-

\footnotetext{
${ }^{7}$ El alojamiento sirve a estos efectos, su propósito es el mantenimiento del poder a través de su manifestación. Se trata de un espacio normado que termina disciplinando las voluntades a fin que los individuos no supongan una traba al engranaje que los dirige a su suministro. La normativa de alojamiento apunta, principalmente, a este objetivo, por lo que su aceptación resulta imprescindible. Cualquier acto de desobediencia a la norma se traduce en una forma de resistencia al sistema que podría tornarlo inoperante, lo que no puede ser sino eliminado. El modo que ha ideado el sindicato para que un reglamento como este sea observado estrictamente por todos los trabajadores, es su consideración como parte integrante del contrato, esto es, como una condición del trabajo. La fuerza que imprime la normativa en los trabajadores queda puesta de manifiesto en estos fragmentos de entrevistas:

"En el momento que uno está aquí, tiene que estar sujeto como a unas... unas normas que tiene uno que cumplir, que uno no puede ir a hacer lo que uno quiera” (Ricardo Pérez, trabajador colombiano).

"Uno tiene que acogerse a las normas, a lo que digan y ya [...] uno está acá y es como dice ahí, en el contrato. Uno es un peón agrario, o sea, está en el campo, lo que sea. Pero ellos son los que mandan
} 
tiva de alojamiento se asemeja a aquella arrancada a los obreros de las fábricas en documentos como los reportados por Engels, mediante los cuales se obligaban a consentir las leyes, por el fabricante dictadas.

De tal modo se presenta, omnipotente, el poder del sindicato, que el incumplimiento de las normas puede derivar en la cancelación del contrato de trabajo ${ }^{8}$. Tal advertencia manifiesta la importancia de las normas en aras a la consecución de un objetivo general, el suministro de trabajadores, útil al logro de la acumulación de capital que pretende el empresario, tanto como al éxito en el desarrollo del sistema que procura tal suministro. Por ellas, tratará de prescribirse conductas que ofrezcan resistencias al sistema, al mismo tiempo que se procurará instituir una pauta de comportamiento por la que será posible constatar el compromiso de su cumplimiento, que el trabajador adquirió en el momento de ser reclutado. Mediante la instauración de este dispositivo el sindicato trata, al igual que los industriales del siglo XIX, de eliminar "aquellos hábitos de trabajo y vida de la mano de obra que se oponían al control capitalista del proceso productivo. [...] [Y] educar al trabajador en una sintaxis de conductas, laborales y no laborales, que resultasen adecuadas a las exigencias del movimiento de valoración del capital" (Sierra Álvarez, 1990: 80).

El conjunto de obligaciones que vienen especificadas en este reglamento sugieren la imagen de un trabajador modelo que la disciplina intenta producir por el bien

[refiriéndose a Unió de Pagesos] y hay que acogerse a las normas porque uno está acá para cumplirles a ellos" (Jorge Rodríguez, trabajador colombiano).

"No sé cómo puedo explicar, pero, como la mayoría... para conseguir otro contrato no pueden decir nada, pero de pensar... jclaro! Es algo como... como coges un pájaro y lo metes cerrado en un sitio y no puede volar ni nada. Es un poco dificil. Uno se siente como... la libertad falta" (Julian Ion, trabajador rumano).

${ }^{8}$ Dentro del repertorio de amenazas vertidas por Unió de Pagesos ante el incumplimiento de la normativa de alojamiento se encuentra la cancelación de la relación que une a trabajadores y sindicato, lo que se traduce en el cese de la relación contractual con los empresarios agrícolas, y la devolución al país de origen. En efecto el recurso a la amenaza se consigna como la principal técnica disuasoria frente a posibles comportamientos que pongan en punto de quiebre la calidad del servicio entregado a los agricultores y la capacidad de control de los trabajadores requerida por el Estado. Queda esto de manifiesto a través de las entrevistas efectuadas a los trabajadores:

"Nos presionaban diciendo que si no hacíamos las cosas bien nos devolvían a Colombia" (Dani Barroso, trabajador colombiano).

"Porque tú haces un paro, o alguna cosa, y la solución que hicieron es esa: mandarle de una vez para el país de donde es uno, y asi ellos se cuidan que alguien más lo vaya a hacer, incluso después lo dijeron [...] que si hacíamos paro nos sacaban para Colombia" (Amador Ribera, trabajador colombiano).

"Habia una sola ducha para doce personas y una nevera pequeña, con agua caliente, pero no llegaba para toda la gente [...] Y un chico colombiano, no recuerdo como se llama, le ha dicho a UP que estas condiciones no son buenas, no puede vivir tanta gente en una caravana. Vinieron de UP no me recuerdo... y con los de la empresa le han dicho, si no te conviene prepárate tu maleta y para Colombia [...] el resto se han quedado asustados, entonces toda la gente no dice nada, les ha dado miedo para hablar" (Julian Ion, trabajador rumano).

"Si me rebelo mucho, lo primero que me dicen, estás hablando mucho, pues mañana mismo te vas para Colombia" (Ernesto Suárez, trabajador colombiano). 
del sistema. El propósito de su producción se relaciona con viejas prácticas disciplinantes que "en conjunto, en su estrecha articulación, perfilaban una meta única y precisa: la producción del obrero modelo" (Sierra Álvarez, 1990: 83). Cada una de estas normas se orienta, de un modo más o menos explícito, a la adaptación productiva del trabajador. Desde este punto de vista, la disciplina dispuesta en el marco del alojamiento hace retornar a nuestra memoria las prácticas disciplinarias paternalistas que, en contextos de escasez de mano de obra, industriales del pasado instauraron al interior de los diversos tipos de habitaciones obreras por ellos entregadas.

\section{Reterritorializando el flujo de extranjeros: táctica para el consumo intensivo de mano de obra}

Este trabajo se coloca en el terreno de las reflexiones sobre la territorialización de los seres humanos con el fin de ejercer un tipo determinado de dominación, es decir del espacio no sólo como escenario, sino también como instrumento para garantizar la sumisión humana. Cómo el territorio puede ser organizado para ese fin y, más en particular, cómo deviene en un caso específico un medio de coerción, sobre todo cuando, como en la cuestión que se aborda - la de los alojamientos dispuestos por la Unió de Pagesos para concentrar a sus contratados-, parecen especialmente dispuestos para asegurar el escrutinio y el control constantes sobre los hospedados. La compleja red de vinculaciones, surgidas al entorno de la delegación que hace el Estado al sindicato de representatividad legal empresarial y función pública ${ }^{9}$, determina una posición específica para cada agente, cuyo contenido se expresa en cotas desiguales de poder. El sindicato ostenta, dentro de este esquema de relaciones, una posición hegemónica, lo que le permite desarrollar una notable función normativa, tanto del modo en que el resto de actores deben relacionarse, como del

\footnotetext{
${ }^{9}$ La Gestión Colectiva de Trabajadores, procedimiento establecido para la contratación en origen de temporeros agrícolas es el marco jurídico que promueve esta transformación de las organizaciones empresariales agrícolas en agentes reclutadores de mano de obra en origen. A través del mismo se construye el estatuto jurídico del temporero contratado en origen, y se formaliza el modo en que debe este tipo de contrataciones debe realizarse, a la vez que se entrega a los sindicatos el poder para contratar en nombre de diversos empresarios agrícolas y para controlar el regreso obligado de los trabajadores una vez expirado el período de las autorizaciones de trabajo. Este poder delegado se traduce en el otorgamiento de representatividad legal y función pública. Esto es así debido a los límites para contratar en origen que impone la legislación a los empresarios individualmente considerados y a las obligaciones de los trabajadores de residir en los alojamientos para ellos previstos y de retornar a su país de origen una vez finalizados los trabajos a ellos encomendados. De tal modo, los trabajadores que obtengan una autorización de residencia y trabajo en relación con una oferta de empleo de carácter temporal deberán regresar a su país una vez finalizada la relación laboral, en cumplimiento de lo establecido en el artículo 56.1.c) del Reglamento de la Ley Orgánica 4/2000, de 11 de enero, aprobado por Real Decreto 2393/2004, de 30 de diciembre, según se hace constar en el Artículo 1. Punto 3. (BOE 30/12/2010).
} 
espacio en el que el sistema se implementa ${ }^{10}$. En su desarrollo, el trabajador debe asumir el rol que le ha sido asignado, cual es el de elemento parte de un colectivo dispuesto a ser almacenado y distribuido. Así, el alojamiento es el lugar privilegiado para la observación del modo en que opera el poder del sindicato sobre los trabajadores. A través del mismo se imprime una huella indeleble sobre los hombres que lo ocupan, en adelante, compelidos a aceptar cualquier condición en el desarrollo de su vida y su trabajo, bajo amenaza de la pérdida del mismo, del retorno al país de origen y de no volver a ser reclutados ${ }^{11}$.

La interpretación que desarrollamos sobre el alojamiento como un dispositivo de poder dispuesto por la Unió de Pagesos descansa sobre todo un corpus teórico dedicado al análisis de la disciplina, entendida como una estrategia de dominación, dirigida al propósito de la producción tanto de sujetos como de bienes. El concepto de poder desarrollado por Foucault resulta aquí estratégico. Efectivamente, es en relación con el resto de agentes, en la pequeña comunidad que conforman, que el sindicato explota su poderío, dirigido al encauzamiento de la conducta (Foucault, 2000: 175) de cada uno de ellos. Sólo así, en relación con los demás, logra producir los efectos deseados de disciplinamiento y transformación del sujeto. En este entramado es el sindicato el actor que detenta el poder disciplinario con el que pretende la intensificación de las fuerzas productivas del trabajador. Todo el sistema depende de la transformación del sujeto, pues, en la medida en que manifieste sumisión y obediencia es que va a ser posible su suministro y distribución. Diremos entonces, que el alojamiento es un lugar destinado a la vigilancia y control de las conductas, a la comprobación del estado de docilidad, que deben presentar los trabajadores, y a su normalización. También está orientado el alojamiento a la disminución de su resistencia, tanto como al aumento de su rendimiento y utilidad, a lograrse mediante su suministro. Este sistema disciplinario se erige en torno de una estructura reticular de alojamientos por los que el trabajador debe ser moviliza-

\footnotetext{
${ }^{10}$ Siguiendo a Gualda Caballero y Ruiz García (2004), este tipo de organizaciones empresariales poseen un rol crucial en el diseño de políticas migratorias. Apoyándose en la producción científica de autores como Gordon, Portes, Sassen, Mendoza y Blanes, las autoras apuntan lo siguiente: "[L]as acciones estratégicas de éstos sobre el reclutamiento pueden ser cruciales para iniciar y dirigir los flujos migratorios. Estas decisiones se encuadran a veces, de forma general, en procesos que vinculan las migraciones internacionales con otro tipo de inversiones productivas en un contexto global [...]" (Gualda Caballero y Ruiz García, 2004: 42).

${ }^{11}$ En efecto una de las condiciones de trabajo impuesta por Unió de Pagesos es la consideración de la huelga y el abandono de trabajo como un incumplimiento de los contratos que los trabajadores suscriben con los empresarios. Asimismo, como ya hemos visto, la normativa que rige el interior de los alojamientos para trabajadores se considera que forma parte de las condiciones laborales que impone el sindicato. Lo que resulta de todo esto es la privación de la libertad de trabajo, lo que se traduce en la imposibilidad de rescindir contratos y de rechazar voluntariamente aquellos acuerdos contractuales que al trabajador se le ofrezcan, la limitación severa de la libertad deambulatoria, toda vez que ausentarse del alojamiento - haciendo caso omiso a la normativa que rige el espacio - está prohibido, así como el cercenamiento de la libertad de elección de domicilio.
} 
do. De otro modo, el alojamiento constituye ese lugar a ser normalizado por el que va a ser posible erradicar la presencia de una figura aborrecible, la del extranjero nómada, y reemplazarla por el trabajador sumiso ${ }^{12}$.

El sindicato, gracias a este prodigioso equipamiento, realiza el sueño empresarial de la fijación del trabajador aplicando a sus cuerpos la disciplina maquínica propia de la fábrica. Los únicos movimientos que, en adelante, le serán permitidos no son otros sino los dictados por el ritmo de conexión de las campañas agrícolas. Este sistema de movilización y suministro se desarrolla con el objetivo de eliminar por completo los movimientos innecesarios que, con anterioridad al mismo, realizaban los hombres libres. Su propósito, como lo es el del sistema de organización racional del trabajo concebido por Taylor, no es otro sino la aplicación al máximo de su potencial productivo, que se deriva tanto del hecho de ser trabajadores sumisos y dóciles, como de la movilización forzada de sus cuerpos. En efecto, el trabajador es el sujeto que el alojamiento promete producir para ser suministrado en forma de insumo agrícola a consumirse por el empresario. El uso al que está destinado el alojamiento, y la razón de su instalación, no es otra sino la producción de un trabajador dócil y sumiso que no genera resistencia, ni contra el sistema que lo recluta y disciplina, ni contra el orden social que por él se trata de reproducir. Entendemos entonces que el alojamiento no es sino un medio de producción de figuras y reproducción de órdenes sociales. Es una herramienta cuya dinámica se basa en la puesta en circulación de los trabajadores con el objeto de crear unos flujos que de forma eventual van a ser cristalizados, puestos en reserva. La afirmación de Fourquet

\footnotetext{
${ }^{12}$ La normativa no es sino una condición de trabajo más, que los trabajadores aceptaron acatar: "Es muy importante que cumpláis la normativa de alojamiento, pensad que, junto a las condiciones laborales, forman parte del contrato. Si se incumplen las normas puede rescindirse la relación laboral" [Información hallada en documentación interna suministrada por Unió de Pagesos en la que se especifican pautas de gestión del alojamiento]. El recurso a la intimidación es el método óptimo para la supresión de cualquier atisbo de levantamiento. La posibilidad de ser enviado al país de origen y no volver a ser contratado por el sindicato quebranta el ánimo de aquellos que niegan su existencia cosificada, pues aquellos que fracturan el ritmo impasible de la cadena corren el riesgo de ser considerados sujetos conflictivos. De tal manera han advertido la intimidación y el ejercicio del poder los trabajadores contratados por Unió de Pagesos:

"Si hay un problema te vas a Rumanía" (Mijaíl Stoica, trabajador rumano).

"Uno no vuelve el próximo año, es la realidad. Estamos muy intimidados. Creen que los que venimos aqui somos personas ignorantes" (Ernesto Suárez, trabajador colombiano).

Tanto es así que este último trabajador entrevistado tomó precauciones durante nuestra entrevista como la que se transcribe a continuación:

"Lo que estoy diciendo en esta entrevista no se lo puedo decir a nadie más, porque en el momento que sepan quién dice todo esto, no volveré más. Es la verdad, hay que ser realistas. No podemos decir más" (Ernesto Suárez, trabajador colombiano).

De forma mucho más explícita, Julián Ion describe el sentimiento que suscita en los trabajadores la intimidación a que son sometidos:

"Miedo, no tienen que hablar mucho si quieren venir otra vez. (...) te encuentras como atado con las manos, atado. Y no puedes hablar nada porque si hablas vas a perder el trabajo, te quedas sin trabajo, jeso es! Siempre te da miedo eso" (Julian Ion, trabajador rumano).
} 
adquiere en este contexto una importancia radical: "La función de los equipamientos colectivos es registrar, fijar, almacenar los flujos" (Fourquet y Murard, 1978: 28). Cada nódulo-alojamiento es expresión de una fijación necesaria al suministro y a la imposición de disciplina. Efectivamente, el alojamiento re-territorializa el flujo de la figura inoportuna del extranjero, lo bloquea, y en ese almacenaje lo disciplina para su transformación, funcional a la reproducción del sistema que los domina y el orden productivo que los devora.

Existen diversos tipos de alojamientos: los dispuestos por las empresas del sector agropecuario, los que de manera individual entrega un empresario agrícola para el cobijo de los trabajadores por él contratados y los alojamientos comunitarios de titularidad municipal dispuestos para una gran cantidad de trabajadores reclutados por la Unió de Pagesos que serán distribuidos al grueso de empresarios demandantes de mano de obra al servicio de contratación del sindicato. El alojamiento comunitario es, de todos los equipamientos que gestiona el sindicato, el más conveniente para la realización de la circulación constante y sistematizada de los trabajadores, por la que se hace fluir de manera ordenada la fuerza de trabajo entre los empresarios agrícolas. Se trata de un modo particular de consumo productivo de la fuerza de trabajo obrera, táctica de encuadramiento obrero por el que van a evitarse aquellos desajustes producidos por una movilidad autónoma: "Estos desajustes en el flujo de los diferentes elementos que intervienen en un montaje dado traen consigo inmovilizaciones de capital y «retrasos» en el ciclo de la producción” (Coriat, 1982: 51). El alojamiento colectivo, como nódulo distributivo de trabajadores, los previene y favorece la creación de una cadena de suministro que guarda similitudes con las líneas de montaje industriales. En ambos casos se trata una gestión del capital circulante dirigida al incremento de la productividad de los elementos que integran la producción. El trabajador es uno de ellos y el alojamiento el dispositivo necesario para la rentabilización del sistema y a su explotación, realizada cuanto mayor es la tasa de circulación y puesta al trabajo de la mano de obra.

En este contexto, el trabajador se cosifica más que nunca, transformándose en un bien perteneciente al sindicato, gestor del alojamiento. Este bien será distribuido entre los usuarios del sistema lo que convierte a este equipamiento en un centro de almacenaje y distribución de la fuerza productiva. Lo comunitario, de este modo, hace referencia a una necesidad de coerción, no sólo por el volumen de hombres allí concentrados, sino por el tipo de sujeto que se concentra. En este sentido adquiere el término comunitario un cariz represivo, por lo que estaríamos de acuerdo en confirmar con Fourquet y Murard, que "estas nociones — «social», «colectivo»encubren la dimensión de obligatoriedad que atraviesa a todo el concepto de equipamiento colectivo" (Fourquet y Murard, 1978: 151). 
En su interior, el poder del sindicato se encuentra establecido con el objetivo de la docilización del que allí se aloja. Un poder disciplinario que se ocupa de la corrección de las conductas de los individuos que implican una resistencia al sistema que los ha reclutado, movilizado y, posteriormente, concentrado ${ }^{13}$. Originado en la delegación estatal de función pública, este poder sirve tanto a la ejecución constante del suministro de trabajadores, como al control contra el éxodo. Principal función del mismo es la de "enderezar conductas [...] No encadena las fuerzas para reducirlas; lo hace de manera que a la vez pueda multiplicarlas y usarlas. Encauza las multitudes móviles, confusas, inútiles de cuerpos y de fuerzas" (Foucault, 2000: 175). Los individuos allí dispuestos desarrollan sus vidas siguiendo un modelo de conducta previamente determinado, ejecutando órdenes que destruyen, una y otra vez, cualquier atisbo de autonomía. La disciplina es la técnica requerida por este tipo particular de poder dirigido al uso productivo de las fuerzas de aquellos sujetos cuya libertad ha sido exorcizada. Así, transformados en objetos, a través de la mecánica que emplea para el logro de sus objetivos - en instrumentos de su ejercicio, tomando la expresión de Foucault-, el sindicato establece un orden productivo. El encuadramiento de los hombres dentro de la organización, la normativización del espacio y la supervisión ejercida por personal encargado, son parte fundamental de su mecánica ${ }^{14}$. A través de estos procedimientos el sindicato previene conductas y reajusta el contenido de las relaciones, posicionando nuevamente al infractor de órdenes y normas bajo su dominio. Pretende, al fin y al cabo, la realización uniforme, por parte de los trabajadores, de una acción preceptuada, o como bien señala Weber, a propósito de su estudio sobre la significación de la disciplina, persigue "la uniformidad de la obediencia por parte de una multiplicidad de hombres" (Weber, 2008: 882). La disciplina se presenta, entonces, como la condición sine qua non

\footnotetext{
${ }^{13}$ Sobre la corrección de las conductas, Moreno Nieto (2009) identifica la aplicación de medidas disciplinarias por parte de los empresarios onubenses, que exceden el ámbito de la relación laboral siendo de interés la vigilancia de las actividades desarrolladas en la esfera privada del trabajador: "Cabría, asimismo añadir otra característica que nos parece esencial para completar la idea del estatus cautivo de estas trabajadoras y es que no existe una nítida separación entre su vida laboral y su vida privada en los campos agrícolas onubenses [...] En este contexto, se valoran los comportamientos de las trabajadoras en su tiempo libre para medir el potencial rendimiento del trabajo" (2009: 74).

${ }^{14}$ Los trabajadores, bajo este sistema, intentan adaptar su conducta a un modelo predeterminado con el fin esencial de no ser retornados, lo que supondría perder el trabajo y la posibilidad no volver a ser reclutados por el sindicato. El protocolo que se sigue en situaciones en las que los trabajadores incumplen la normativa es el siguiente:

"Si alguien se salta la normativa, normalmente hablas primero con ellos y se les pregunta por qué lo han hecho, ¿no?, que motivos tienen. Normalmente lo habla la encargada, si la encargada no logra solucionar el problema habla con el técnico de zona y si no pues voy yo. Yo digo, mejor que no me veáis, porque si me veis... Se les avisa, se habla con ellos y si no se consigue nada, los enviamos para casa, que esto es lo último de todo, ¿no? El contrato se rescinde, porque ellos han firmado una normativa con unas condiciones, si no se cumple esto, lógicamente se les envía a casa" (Josep Barceló, Servei de Contractació de Treballadors).
} 
para la puesta en marcha de un movimiento calculado de la mano de obra, un acicate al trabajador dirigido a la integración de cada uno de ellos en el orden impuesto, que implica su "adiestramiento con vistas al desarrollo de una presteza mecanizada por medio de la práctica" (Weber, 2008: 882).

El suministro que promete el sistema y la necesidad de un espacio ordenado a tal fin debe concretarse. Para ello, un cálculo racional al respecto de las conductas, acciones, e itinerarios se ha realizado; lo siguiente consiste en "el adiestramiento mecanizado y la inserción del individuo en un mecanismo inevitable que le obliga a «marchar al paso», que fuerza al individuo incorporado a una organización a adaptarse a una totalidad de un modo, por decirlo así, forzoso" (Weber, 2008: 883). Este disciplinamiento pone en relación distintos modos de organización productiva aparecidos en diferentes tiempos históricos cuyo modelo ejemplar ha sido, y es, la disciplina militar. En las villas romanas, como en las empresas industriales capitalistas modernas la racionalización del uso de las fuerzas, el modo preciso en que deben aplicarse al trabajo, refiere a un cálculo proyectado para la rentabilización del capital invertido en las mismas y la obtención de la mayor cota de plusvalía.

\section{Conclusiones}

La introducción de un sistema de reclutamiento y suministro como el que implementa el sindicato Unió de Pagesos en Cataluña, perturba el esquema jurídico imperante toda vez que produce un sujeto cuyo estatuto jurídico se configura fácticamente, fuera de toda legalidad, según el poder creador del sindicato. En efecto, cabe preguntarse en estas conclusiones cómo es posible y qué es lo que ha posibilitado que una organización sin legitimidad política termine fijando los derechos y deberes que configuran las libertades de los trabajadores por ella reclutados. Las facultades y obligaciones concretadas por el sindicato, a través de reglamentos de régimen interno de alojamiento y condiciones de trabajo, nos lleva a concluir que su estatuto es diverso tanto del de aquél que goza el extranjero residente, en ningún caso limitado en el disfrute de los derechos que amparan el ejercicio de sus libertades, como del que sufre el extranjero en situación irregular, directamente privado de determinados derechos como el de circulación y trabajo, y cuya libertad es meramente fáctica. A diferencia de éstos, su estatuto viene definido merced el poder del sindicato. Condenados a satisfacer las necesidades de un sector económico que intenta escapar a su reconversión, su existencia transcurre en la indeterminación del régimen particular al que debieran encontrarse afectos. De tal modo, cualquier tipo de institución interesada en servirse de ellos aprovechando su posición vulnerable puede hacerlo, obteniendo así beneficios de diversa índole, económicos o políticos, como sucede con la Unió de Pagesos.

Las consecuencias que de esto se derivan en lo referente al mercado de trabajo son relevantes a esta investigación, por la que concluimos que la producción de 
sujetos limitados en derechos auxilia al sector agrícola en su intento por sustraerse al mismo. La necesidad de mano de obra fijada al sector agrícola a través del modelo de contratación en origen, por el que la Unió de Pagesos implementa su sistema, se pone de manifiesto, igualmente, en el contexto de la crisis económica que afecta a la economía española desde 2008. En efecto, y a pesar de las tasas de paro que rondan el veinte por ciento, ni siquiera el desempleo ha sido suficiente para atraer a los trabajadores autóctonos o en situación regular a participar de modo relevante en las campañas agrícolas de recogida ${ }^{15}$. A pesar que el sindicato declara tomar una opción preferente por la mano de obra local para llenar los puestos de trabajo, éstos, mal pagados e inestables, no parecen captar la atención de la mano de obra local, puesto que "el problema es que la mayoría de la gente no quiere trasladarse al campo para coger un trabajo temporal que además es muy duro" (El País, 9-82010). Por lo demás, los mismos agricultores declaran preferir a los contratados en origen por constituir una mano de obra más estable que la local puesto que, su parecer es "garantía de mano de obra segura" (Diari de Girona, 2-3-2009).

Para estos trabajadores, colocados al margen de la comunidad política, está destinado el ejercicio de un poder soberano que mana de una sociedad a todas luces predispuesta a mermar la calidad de su democracia. El alojamiento, presentado por el sindicato como un ejemplo más de vivienda obrera, no es sino un lugar de encierro productivo, concebido para individuos considerados peligrosos cuya amenaza debe ser conjurada a través de su concentración y su conversión en fuerza de trabajo útil mediante su disciplinamiento, en su interior se desarrolla un régimen cercano al penitenciario productor de sujetos pre-delincuentes, aquéllos sobre los que recae una perpetua sospecha de amenaza contra el orden establecido. Por ella, los efectos derivados tanto de la paulatina desintegración del estado del bienestar, producto de una profunda crisis económica e institucional, como la supuesta peligrosidad social del extranjero, chivo expiatorio de los males que aquejan a la sociedad, se tratan de mitigar relegándolo al espacio del alojamiento. Un lugar cuyos confines vienen definidos por el sindicato merced el poder que le ha sido delegado con el propósito de regular el flujo migratorio y subvencionar la agricultura. Su acción constrictiva de los derechos lo delata como un espacio liminal en el que los individuos se encuentran atrapados, donde no rigen en plenitud los derechos que amparan a los

\footnotetext{
${ }^{15}$ Gualda Caballero y Ruiz García ponen de manifiesto la paradoja existente en el agro español representada por altos niveles de desempleo y demanda de trabajadores agrícolas: "[...] la existencia de fuertes tasas de desempleo en algunos de los países que demandan mano de obra y de población nacional suficiente, en términos absolutos, para ocupar los trabajos demandados no es incompatible con las necesidades derivadas del abandono del campo" (2004: 44).
} 
trabajadores en España, de manera que el estatuto supuestamente legal del que debieran gozar, constituye una mera ficción jurídica ${ }^{16}$.

\section{Bibliografía}

Arias González, Luis (2001-2002) "Se alquilan cuartos interiores económicos. El problema de la vivienda obrera en la España de entresiglos". Studia Historica, 19-20, 81-127.

Bentham, Jeremy (1985) El panòptic. Barcelona: Edicions 62 / Diputació de Barcelona.

Comelles, Josep Maria (2007) Stultifera Navis. La locura, el poder y la ciudad. Barcelona: Milenio.

Coriat, Benjamín (1982) El taller y el cronómetro. Ensayo sobre el taylorismo, el fordismo y la producción en masa. Madrid: Siglo XXI de España.

De Lucas, J. (2004) "Ciudadanía: la jaula de hierro para la integración de los inmigrantes”, en G. Aubarell y R. Zapata-Barrero (eds.) Inmigración y procesos de cambio. Madrid: Icaria-IE Med, 215-236.

Engels, Friedrich (1976) La situación de la clase obrera en Inglaterra. Madrid: Akal Editor.

Foucault, Michel (1991) Saber y Verdad. Madrid: Las Ediciones de La Piqueta.

Foucault, Michel (1995) Un diálogo sobre el poder y otras conversaciones. Madrid: Alianza Editorial.

Foucault, Michel (2000) Vigilar y castigar. Madrid: Siglo XXI de España.

Fourquet, François, y Murard, Lion (1978) Los equipamientos del poder. Ciudades, territorios y equipamientos colectivos. Barcelona: Editorial Gustavo Gili.

Gaudemar, Jean Paul de (1981) La movilización general. Madrid: La Piqueta.

Gaudemar, Jean-Paul de (1991) El orden y la producción. Nacimiento y formas de la disciplina de fábrica. Madrid: Editorial Trotta.

\footnotetext{
${ }^{16}$ De igual forma diversos autores, como por ejemplo De Lucas (2004), constatan las dificultades por parte del colectivo de extranjeros residentes, como de aquellos cuya situación administrativa es irregular, para gozar plenamente de los derechos que la Constitución tiene reservados para los autóctonos. Nuestra interpretación del status jurídico del extranjero contratado en origen consigna la disminución en derechos que también experimenta este tipo de trabajador, aunque de modo diverso a cómo lo hacen el extranjero residente o el "irregular". Efecto de esta merma en la capacidad política del extranjero residente o del "irregular" se manifiesta en los procesos de estratificación cívica a la que está abocados (Torpey, 1998; Kofman 2002; Miravet, 2006; Gil Araujo, 2009). Asimismo, el extranjero contratado en origen sufre una exclusión de la comunidad política a la que arriba pues siquiera, a pesar de poseer el correspondiente permiso de trabajo y residencia, tiene poder para alojarse donde decida, a rescindir contratos de trabajo y a ejercer su derecho de circulación de forma plena.
} 
Gil Araujo, Sandra (2009) "Las periferias de la metrópolis. Políticas migratorias, género y estratificación de la población latinoamericana en España", en G. Cortes y N. Miret (coords.) "Dialogues transatlantiques autour des migrations latino-américaines en Espagne”, Revue des Mélanges de la Casa Velasquez, 39 (1), 57-74.

Goffman, Erving (2007) Internados. Ensayos sobre la situación social de los enfermos mentales. Buenos Aires: Amorrortu.

Gordo Márquez, Mercedes, y Felicidades García, Jesús (eds.) (2009) Explorando los contratos en origen en los campos españoles. Huelva: Universidad de Huelva.

Gualda Caballero, Estrella, y Ruiz García, Marta (2004) "Migración femenina de Europa del Este y mercado de trabajo agrícola en la provincia de Huelva, España”. Migraciones Internacionales, 4, 36-65.

Kofman, Eleonor (2002) "Contemporary European Migration, Civic Stratification and Citizenship". Political Geography, 21, 1035-1054.

Miravet, Pablo (2006) "Algunos problemas para la participación cívica y política de los inmigrantes". Cuadernos electrónicos de filosofia del derecho, 14, 1-24. [URL: <http://www.uv.es/CEFD/14/pmiravet.pdf>. Visitado el 12/03/2012].

Marx, Karl (1972) El Capital. Madrid: Edaf.

Moreno Nieto, Juana (2009) "Los contratos en origen de temporada: Mujeres marroquíes en la agricultura onubense". Revista de Estudios Internacionales Mediterráneos (REIM), 7, 58-78.

Rodríguez, Emmanuel (2003) El gobierno imposible. Trabajo y fronteras en las metrópolis de la abundancia. Madrid: Traficantes de Sueños.

Sierra Álvarez, José (1990) El obrero soñado. Ensayo sobre el paternalismo industrial (Asturias, 1860-1917). Madrid: Siglo XXI de España.

Torpey, John (1998) "Coming and going. On the State Monopolization of the Legitimate «Means of Movement»". Sociological Theory, 3, 239-259.

Weber, Max (2008) Economía y sociedad. México: Fondo de Cultura Económica. 